\title{
Hierarchy in Ceramic Art
}

\author{
İsmail YARDIMCI \\ Uşak Üniversity, Uşak, Turkey
}

\author{
Kadir ERTÜRK \\ Adnan Menderes Üniversity, Aydın, Turkey
}

\begin{abstract}
In this research, the sensory and visual effects of Hierarchy in return to Visual Hierarchy in grading and rating system have been evaluated generally. Hierarchy is in three categories: radial, axial and peripheral. The varieties of Hierarchy may be used in forms and surfaces as well as both in form and surface at the same time together. Information on application forms of Hierarchy, types of Hierarchy and their applications in ceramics art have been presented. Examples of industrial and artistic ceramics works aimed at esthetic and visual concept in modern ceramics comprehension within the scope of defining Hierarchy have been presented.
\end{abstract}

Keywords: hierarchy, koram, visual hierarchy, grading, ceramics art

\section{Introduction}

Hierarchy can be defined as regular measure grading, visual hierarchy, rating, grading and even as just Hierarchy. Hierarchy is a state of order in which two binary opposite extremes of the elements such as form, direction, measure, interval grades from one to another. It inherits the degree gap. The lining of the form from larger to smaller or from smaller to bigger, in the case of intervals from larger to narrower make a regular harmony. In the concept of hierarchy the fact of grading emerges as an essential condition. So hierarchy is a way of regulation can be made through grading. There are three sorts of hierarchy such as radial, axial and peripheral. The best examples of the hierarchy can be seen in the environment. Hierarchy is used to give an aesthetic value and technical specifications when it is applied on the ceramic forms and also it has some varieties. Although there are some kinds of hierarchies which can be seen on the ceramic forms that are using artistic and industrial purposes, these examples disassociate from each other according to their differences in the context of order and direction.

\section{Definition of Hierarchy}

Dictionary definition of hierarchy corresponds to a concept that is the ordination and regulation of power and tasks in social organizations according to the relation of subordination-superordination. The general meaning of Hierarchy is coordination and grading. In the artistic meaning, Hierarchy defines as visual Hierarchy, regular measure grading and rating. In Turkish it is known as the name of Koram especially in artistic meaning.

"In English it is Hierarchy, in French it is Hierarchie and in German it is hierarchie. It is called (in Turkish) Koram, which is a bridge that associates two extreme opposites with each other through grades" (Güngör, 1972, p. 90). It also defines as visual hierarchy or regular measure grading.

İsmail YARDIMCI, Professor, Ceramic Department, Fine Art Faculty, Uşak Üniversity,

Kadir ERTÜRK, Lecturer, Architectural Decorative Arts Program, Karacasu Memnune İnci Vocational School, Adnan Menderes Üniversity. 
The perception of the fragments in the whole according to a certain sequence of priority. There is a development, a growth and enrichment in Hierarchical order that is from fragment to whole. In a Hierarchical construction singular elements constitute sub groups, sub groups constitute main groups and main groups constitute whole with same scheme of integration. (Eczacıbaşı, 1997, p. 795)

There is a meaningful and aesthetic line-up between the two opposite extreme which is in order. If the opposition is only according to measure then there are sequences only from smaller to bigger and Hierarchy becomes to a form of "regular measure grading". If there is a texture difference between two extreme, then the texture of each level should be in the regular grading schedule. If there is a value difference between extremes, then the passage should be provided by lightening or darkening the values in each level, gradually. Whether the sequence between two extreme is dependent on the difference of colour or form, it should be done like others. So, the unchanging conditions in Hierarchy are the opposition and regular levelling between two extreme.

Also one of the other unchanging conditions is the number of parts in Hierarchy that should be three. It is an exception when there is a condition of tonal difference in a scale. The fact that there are only oppositional extremes does not give way to Hierarchy.

The opposition between two extreme cannot be from only the one aspect but more. For example, between two extremes there could be a difference in respect of both form and measure or, both the value or texture, or either value, colour and measure. There could be also other possibilities like texture, brightness etc. that is in question. The difference between two extremes from which aspect that could be, the passage should be provided as the regular levels always forms which are located between two extremes.

Here, it is necessary to make a confused point clear. It is a frequently asked question which comes to the mind that "if regular measure grading is a Hierarchy?" In fact in regular measure grading the objects are sequenced in a line from bigger to smaller or smaller to bigger. But, since in this sequence there is a regular lining condition only from the aspect of measure, there is no necessity to lining from the aspect of form, colour, texture or value. Therefore, the objects which are differentiating with regard to their forms, colours, textures and values, could be in an irregular sequence in respect to their colour, value, texture etc. but because of their regularity from the aspect of measure, it can be regarded as "regular measure grading. (Güngör, 1972, p. 90)

But meantime, since there are no regular differences or grades between levels in respect to the colour, texture, value and form, here Hierarchy emerges only in respect to the measure, but does not emerge in respect to colour, texture, value etc. Thus, not every regular measure grading creates Hierarchy. For example, in an arrangement if there is a colour, texture and value grading with regular measure grading among the forms, there emerges Hierarchy either in form and on surface between two extremes.

While creating Hierarchy, in general forms do not obscure each other. But this is not a condition. Obscuration could be used when it is necessary. There are lots of examples of Hierarchy in nature. The form Hierarchy happens when moon goes from crescent (new moon) to full moon. The states of human, animal and plants in various ages creates a Hierarchy of measure. There are three types of Hierarchy in design. In an arrangement these types could be used same, separately or altogether. (Güngör, 1972, p. 90) 


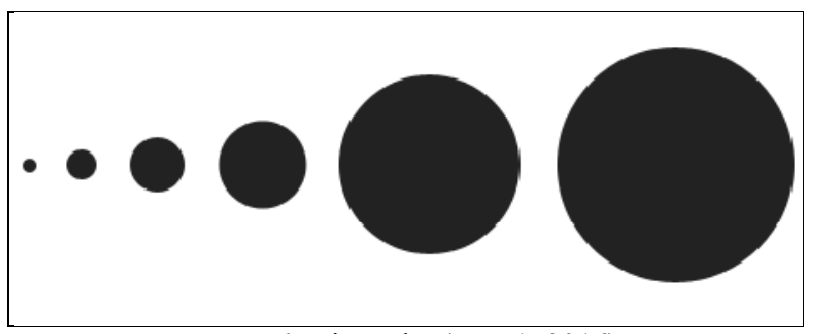

Figure 1. Hierarchy (URL1, 2016).

There are many natural examples of the principle of Hierarchy. Besides, it is possible to see Hierarchy in different disciplines in the domain of art.

\section{The Types of Hierarchy}

Hierarchy is three folded; radial, axial and peripheral. The types of Hierarchy can be used in form or on surface or both in form and on surface separately or altogether.

Radial Hierarchy. "If in an arrangement the forms are growing from center to side or a center point emerges when they are united as to create more than one koram then it is called 'radial koram"' (Deliduman, 2006, p. 32).

The arrangements in which the forms sequenced from center to sides in certain directions from bigger to smaller or smaller to bigger, is called "Focal Hierarchy". There are beautiful examples of the principle of Hierarchy on the earth. The leaves of a flower which is opened from center to sides and sequenced from smaller to bigger etc. (Alpaslan, 2003, p. 75)
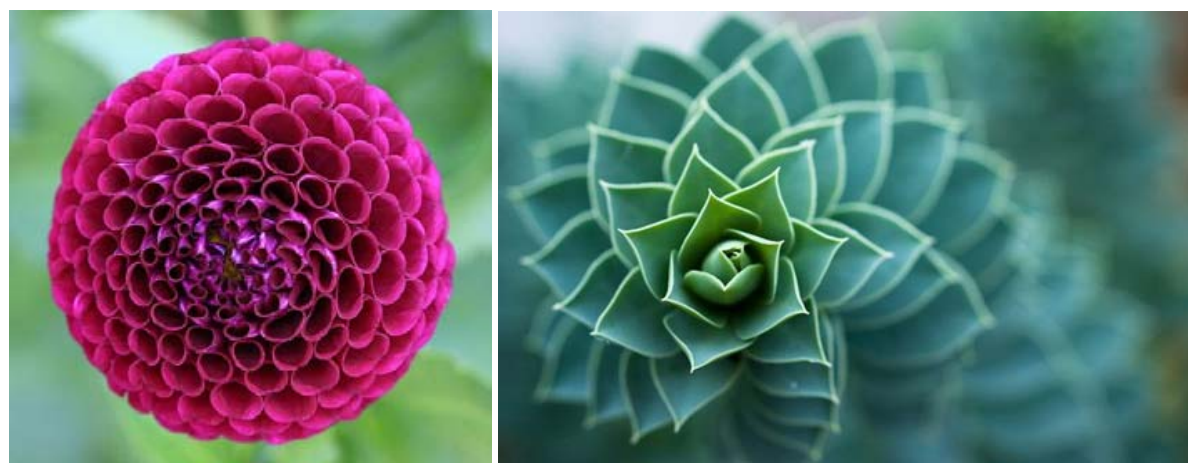

Figure 2-3. Examples to Radial Hierarchy from nature (URL2-3, 2016).

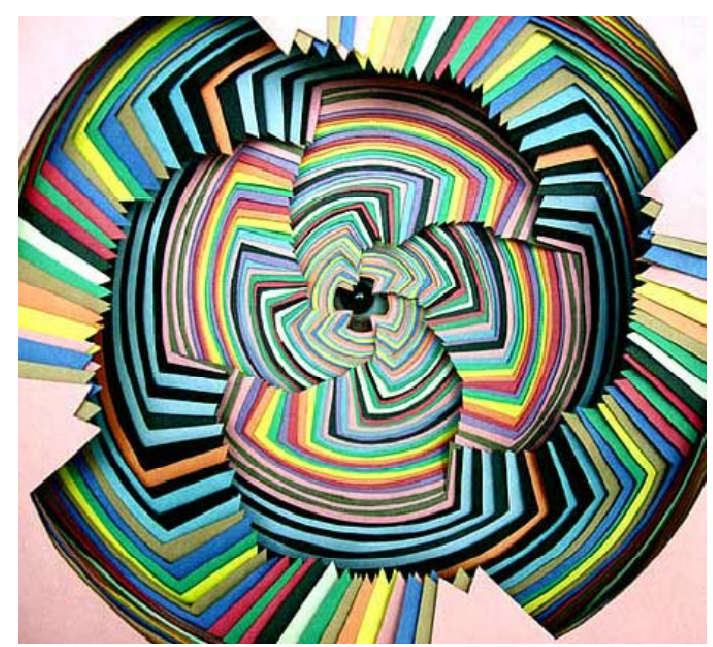

Figure 4. Example to Radial Hierarchy, paper Art, David Report (URL4, 2016). 
The common point of the natural and artistic structures above is, surrounding a center regularly growing through the outside and waning through the inside. Their aspects are from outside and above. In each floor, by overlapping on the middle of each other or without overlapping the distinctness between the levels becomes narrower. By this regulation it is created that an axial Hierarchy is with regard to the vertical direction and radial Hierarchy with regard to the downright projection.

Axial (linear) Hierarchy. "It is called "Axial Hierarchy" when forms lined up on an axis from bigger to smaller. This sequence could be happen either on a straight line or on broken lines" (Alpaslan, 2003, p. 75). Axial Hierarchy is called also Linear Hierarchy in some resources.

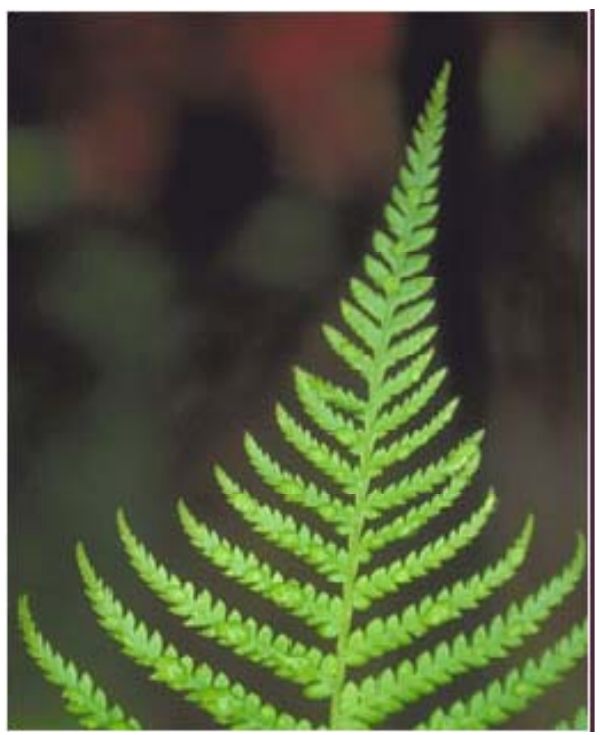

Figure 5. An example to Axial Hierarchy (URL5, 2016).

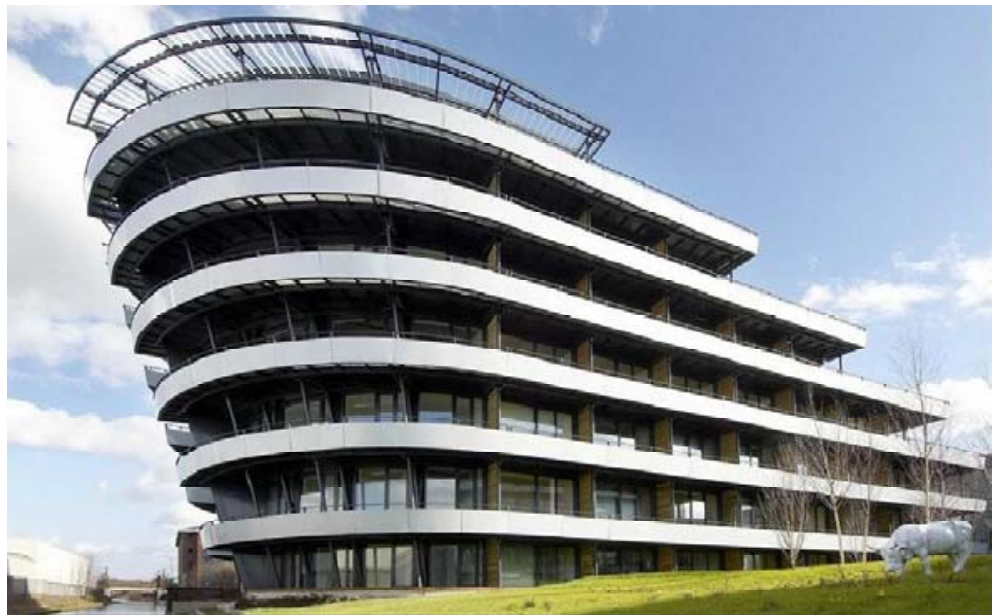

Figure 6. An example to Axial Hierarchy from architecture Waterside Apartment Split Level Concept, ABD (URL6, 2016).

\section{Peripheral Hierarchy.}

"If the forms level over periphery then it is called "Peripheral Hierarchy". Meanwhile the centre to which Hierarchy or Hierarchies are belonged could be in the range or out of the range. The only need is the perception of their dependency to a centre and their move in an orbit" (Güngör, 1972, p. 93). 
Besides, they could be the example of a Peripheral Hierarchy even they are moving in a dispersed orbit (Figures 7 and 8).

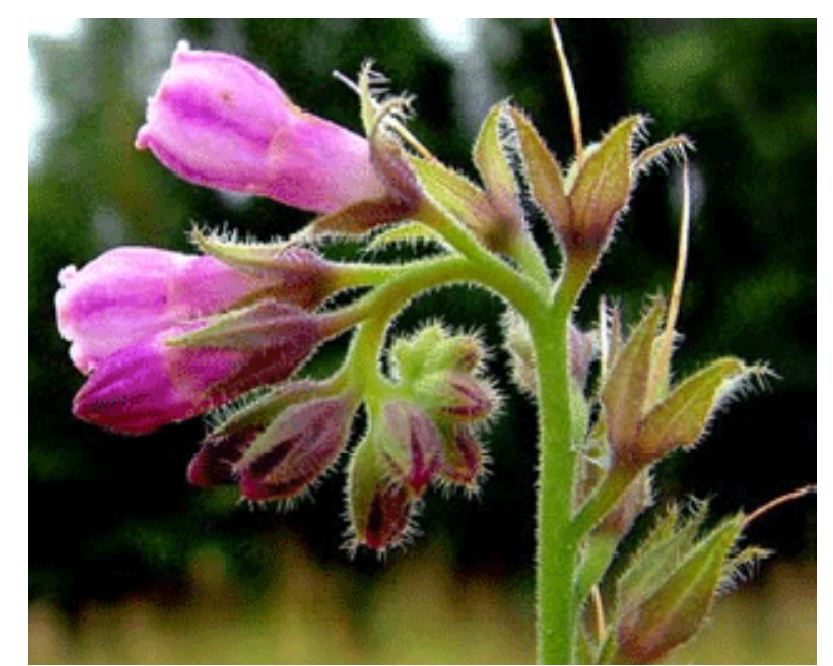

Figure 7. An example to Peripheral Hierarchy from nature (URL7, 2016).

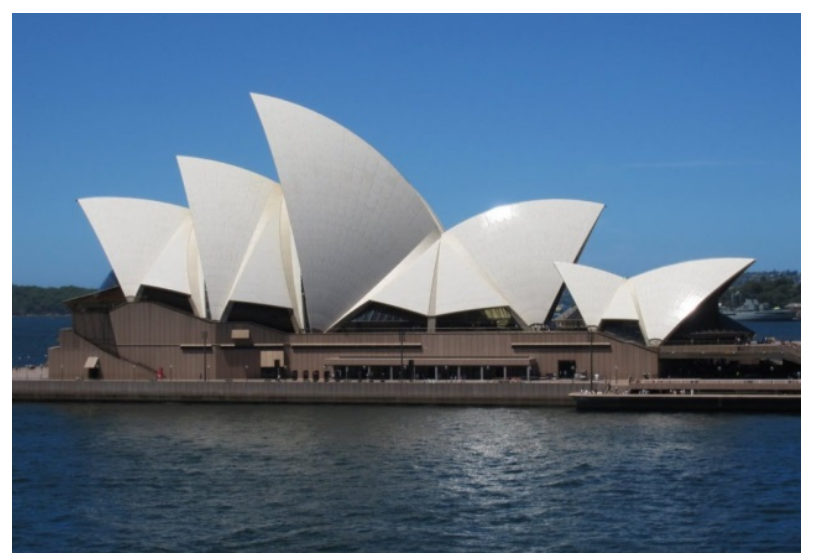

Figure 8. An example to Peripheral Hierarchy form architecture, Sydney Opera House, 1959-73 (URL8, 2016).

In designing these three types of Hierarchy can be used altogether. By benefiting from such arrangements which provides a passage between two extremes in an order, architects, sculptors, ceiling decoraters have given the aesthetics to their works in a most easy way. (Deliduman, 2006, p. 32)

\section{Hierarchy in the Art of Ceramic}

The art of ceramic in its historical development process comes today by effecting from various civilizations and different life perspectives, different techniques and aesthetic values. Today by the conditions and the thought structures of the age, it is still reformatting and constructing its own identity.

"Ceramic; occurs as the production of the goods emanates from necessities in industrial sense and also in the sense art which figures out the pure aesthetic values it occurs as a process of creation" (Yardimc1, 1993, pp. 3-4). When we talk about Hierarchy in the art of ceramics, it is possible to take the subject twofold as artistic and industrial ceramic good. Accordingly;

Artistic ceramics: Shaped with free hands or even shaped with industrial methods but never produced in a serial way and it can be functional, moreover reflecting the sensitiveness, cultural degree, religious beliefs and behaviours of societies, 
briefly the relations and daily life in societies, it is the evaluation of the ceramic material with all its specification; a way of expressing the pure aesthetic and genuine creativeness in its actual meaning. (Yardımc1, 1993, p. 4)

Industrial Ceramic; is an art which is produced with industrial ways, that could be functional in full filing the physical and the psychological necessities of users and user groups, and at the same time it designs the products in which the aesthetical values are balanced. (Yardımc1, 1993, p. 4)

"The art of industrial ceramics, serves the works for necessities, and it is a domain which is realized through the conditions of the market in wholly serial production" (URL9, 2016).

If we define Hierarchy as the regular measure grading between two extreme, we may see that there are many arrangements which are fitted to this definition in the art of ceramics. Although Hierarchy consists of independently sequenced forms between two extremes, in some instances it occurs as contiguous to each other. It is possible to see the examples of Hierarchy in both industrial and artistic ceramic products in form, or on surface and either in form and on surface. Hierarchy can be on texture and on colour.

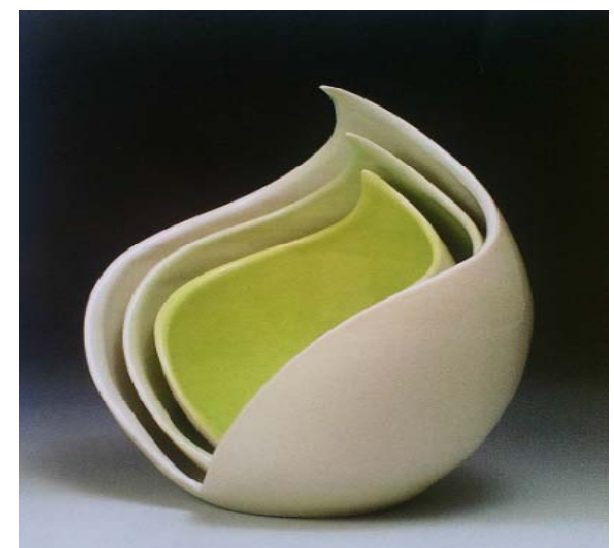

Figure 9. "Reach” (from keep series), Karen Swyler, “Together porcelian”, 28 cm, 2009 (Hatch, 2010, pp. 34-37).

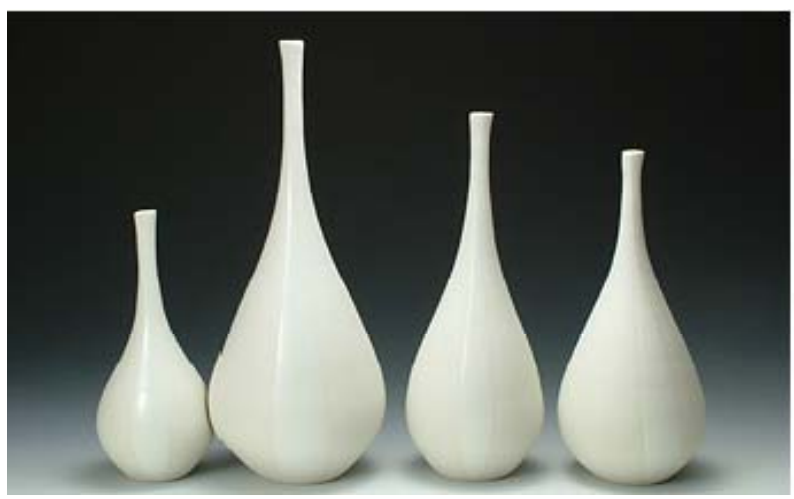

Figure 10. An example for Pheripheral Hierarchy, Karen Swyler, porcelian, 2007 (URL10, 2016).

The example above, on the left, in which a Radial Hierarchy is located is an industrial work of the Karen Swyler. It can be said that there is Hierarchy either in form and colour. The work of the artist on the right is an example of Peripheral Hierarchy and industrial ceramic work.

Artist was born and raised in Long island. Most of his works indicate sharp points reminiscent of the motives of flower or fire. His technique is high heated porcelain formed through the industrial method. 


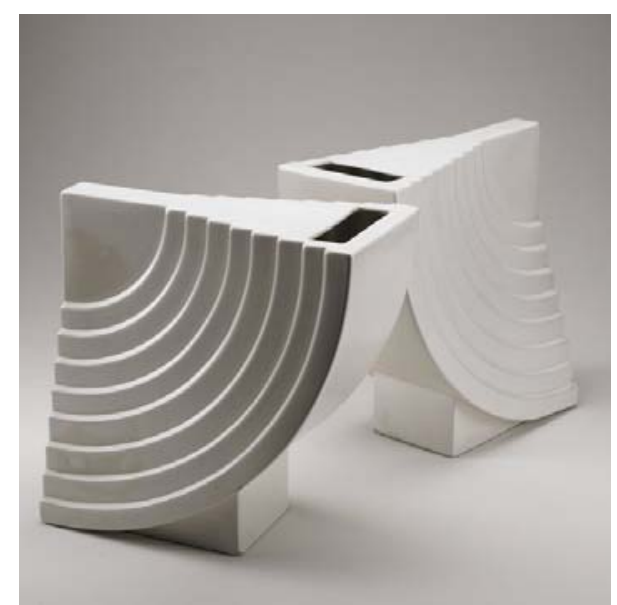

Figure 11. "Yantra vases", EtoreSottsass (URL11, 2016).

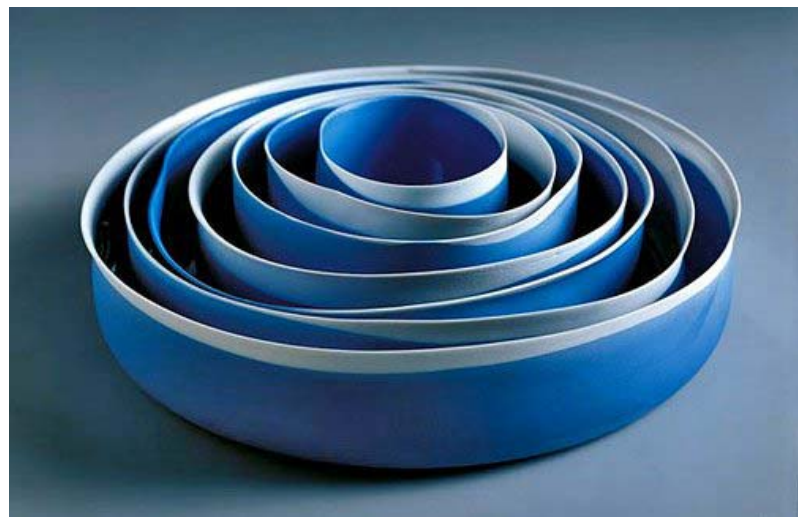

Figure 12. An example of Radial Hierarchy, "7 in1”, Piet Stockmans (URL12, 2016).

The work of Piet Stockmans that you see above on the left is an industrial and functional product. The relief seen on the surface is an example for the Radial Hierarchy. Again there is a function the arrangement on the right above that consists of the entwined forms and its form is the example of Radial Hierarchy. It is an order which is created through expanding around a certain centre point.

Piet Stockmans, was born in Leopolds in1940. He made studies on industrial and ceramic designing domains in various places. Also he made jury membership in ceramic competitions around the world and since 1989 he has continued his works as independent designer. (URL13, 2016) 


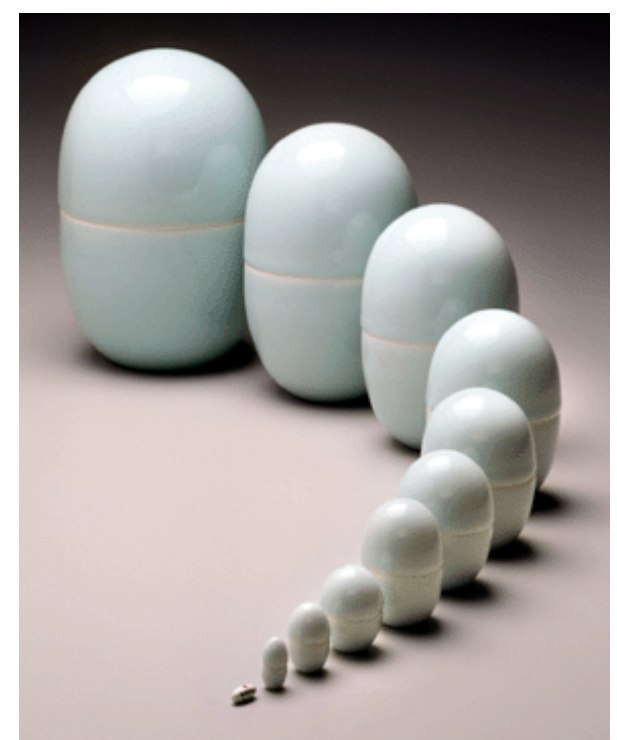

Figure 13. "Nestingcoveredboxes (Irekofutamono)" Yagi Akira, porcelain, 1994 (URL14, 2016).

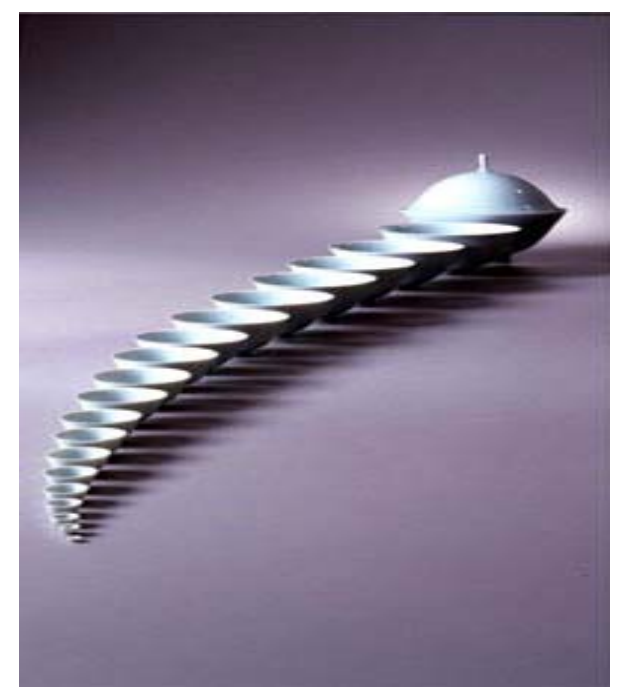

Figure 14. An example of Axial (linear) Hierarchy, "Nesting bowls", Yagi Akira (URL15, 2016).

These examples above that can be seen as Axial Hierarchy are both industrial and functional works (Figures 13 and 14). Each of the ceramic forms that are sequenced through on an axe is smaller or bigger than the other and the degree differences between them are always proportional. It is also aesthetic visually the levelling of the forms of Yagi Akira which are sequenced through an axe in such a regularity.

Yagi who was born in Kyoto, is graduated from Kyoto Government Ceramic Institution. Yagi Akira focuses in his work the discovering of the structured problems. He is versatile in his style, he constitutes his aesthetic understanding by the inspiration of east Asian art and architecture as well as that of Western. (URL16, 2016) 


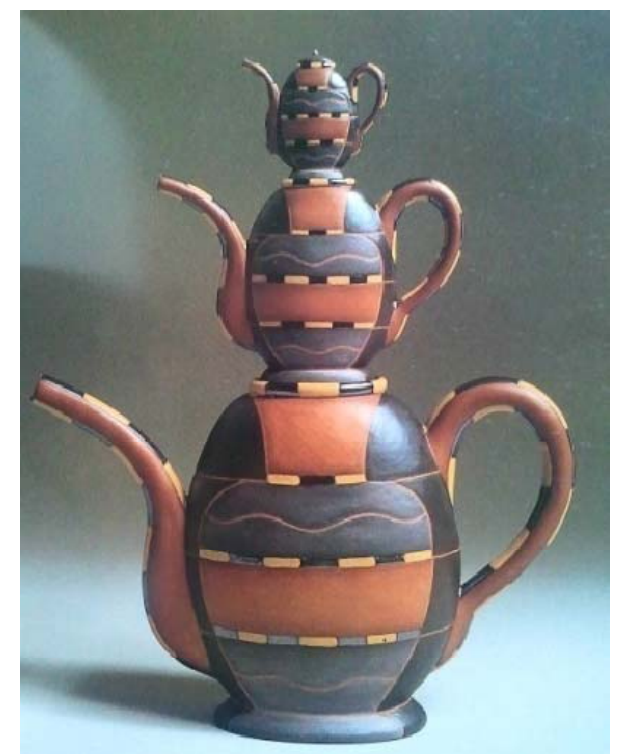

Figure 15. Terracota Withterrasigillat Milan GailBusch, h. 22.5 cm, USA, 1993 (Dormer, 1994, p. 205).

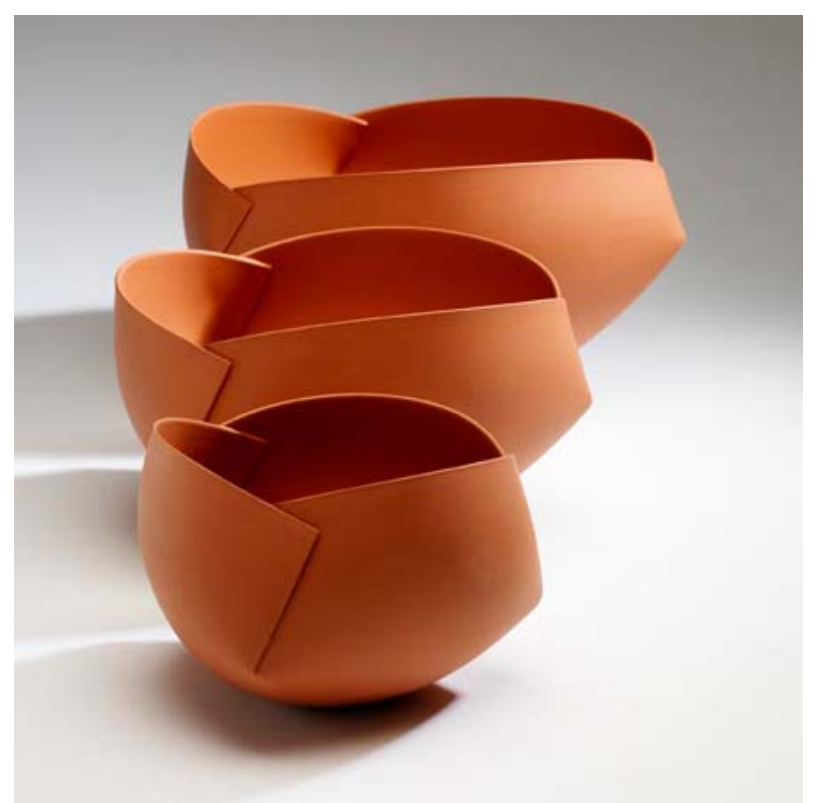

Figure 16. "Moments of growth", Ann Van Hoey (URL17, 2016). 

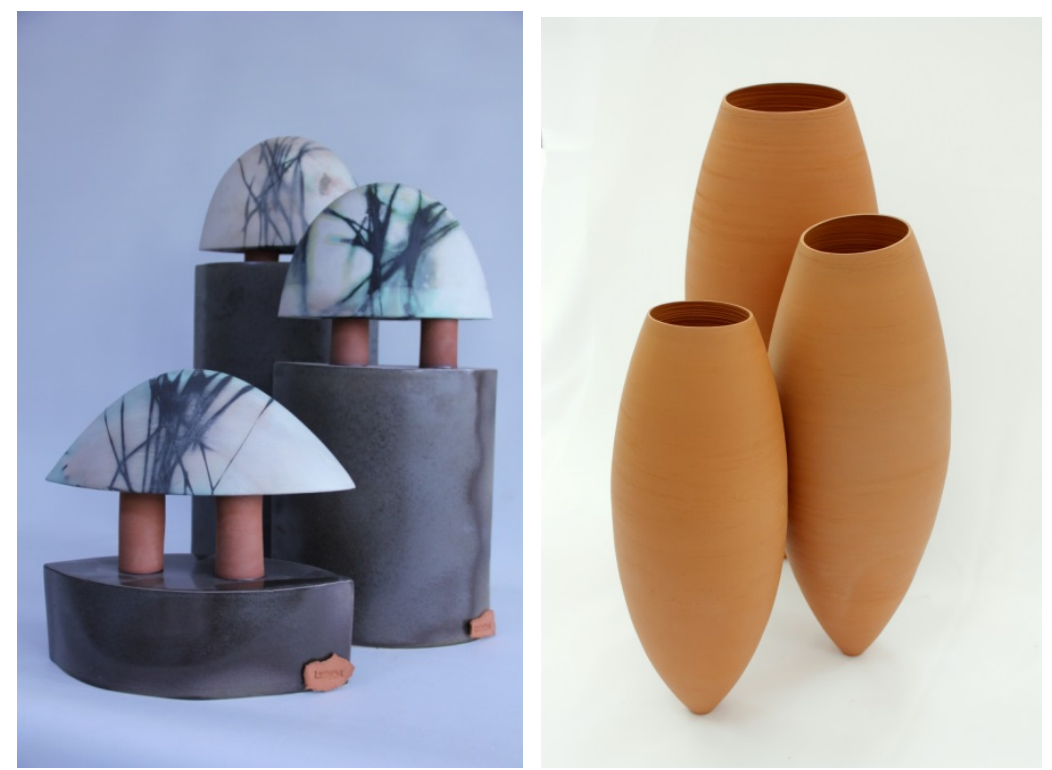

Figure 17. Sagar andGlazed, İsmail Yardımc1, 2016.

Fgure 18. "Triple", Kadir Ertürk, 2011.

The Hierarchy of measure grading of the forms, as it is seen above, are the examples of Axial Hierarchy. On the one side it is not bothering the eye that is the measured passing through the differences of size and it also constitutes a cohesion and unity on the other. The example, on the left side Hierarchy can be seen both in form and on surface. However in the example which is on the left side there is Hierarchy only in form.

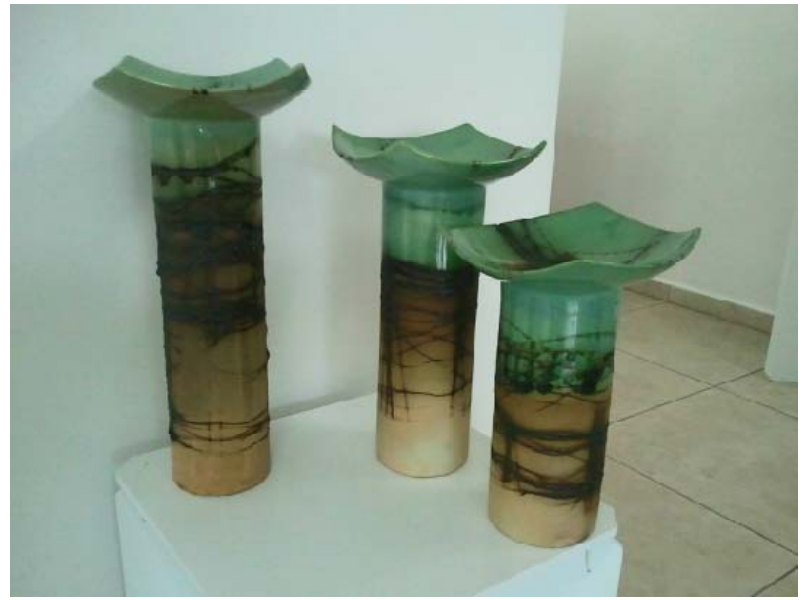

Figure 19. GlazedSagar, İsmail Yardımc1, 2011 (From İzmir Exhibition of Kedi Sanat Gallery). 


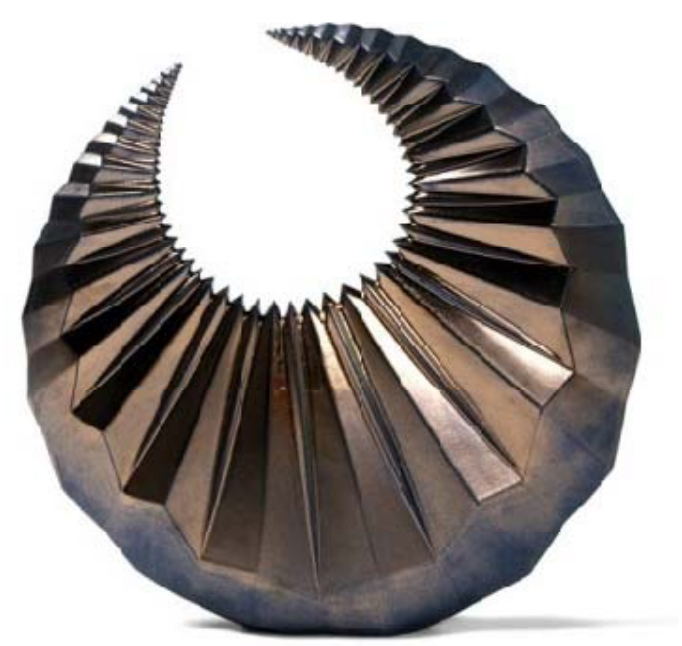

Figure 20. Minkyu Lee (URL18, 2016).

The work above is the example of an artistic ceramic which is produced by industrial ways (Figure 18). It can be seen that the sequence of the forms are Hierarchy and they are rounding by a center. It is at the same time an example of Peripheral Hierarchy whose centre is out of the field. It is a powerful example that Peripheral Hierarchy applied in one form but on the surface.

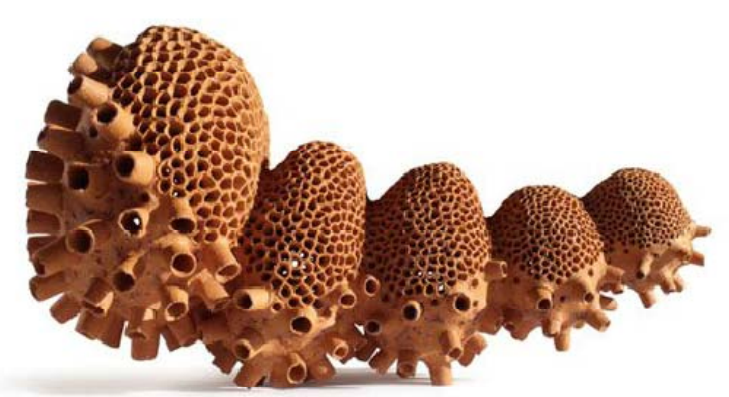

Figure 21. Gabrielle Baecile (URL19, 2016). 


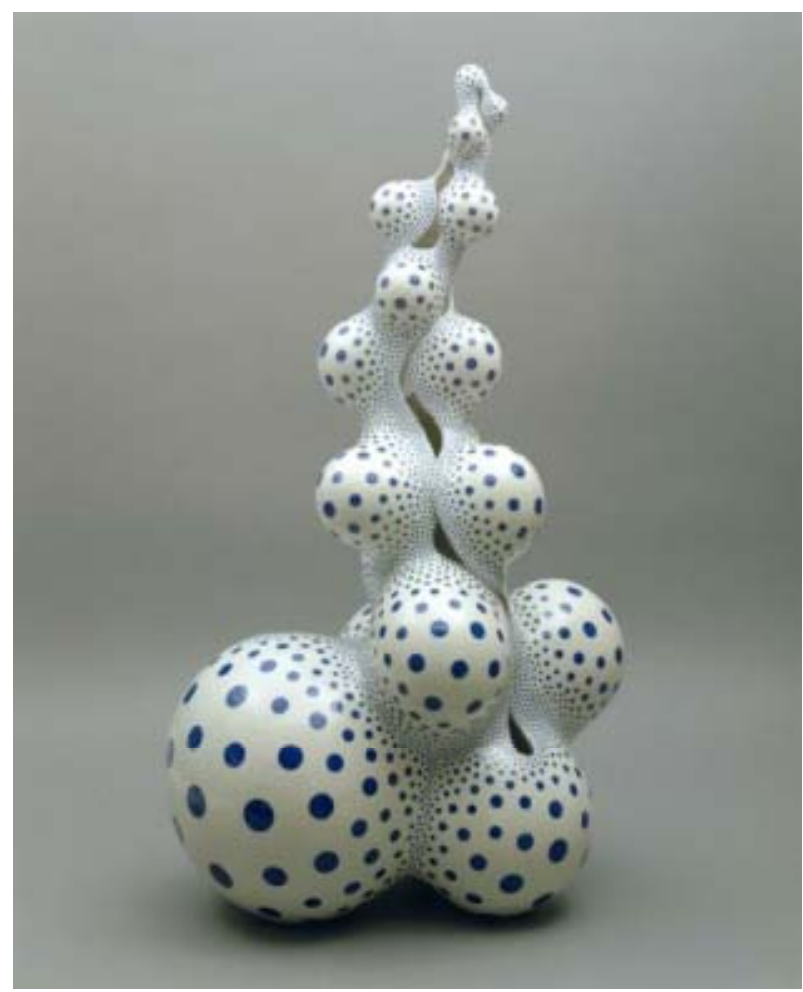

Figure 22. Harumi Nakashima (URL20, 2016).

In some situations like above, forms can create Hierarchy by being contiguous to each other (Figures 19 and 20). In these artistic examples in which Hierarchy is both in the form and on the surface; form creates Hierarchy by waning or expanding on the one hand, on the other the decors and textures create Hierarchy on the surface by waning or expanding.

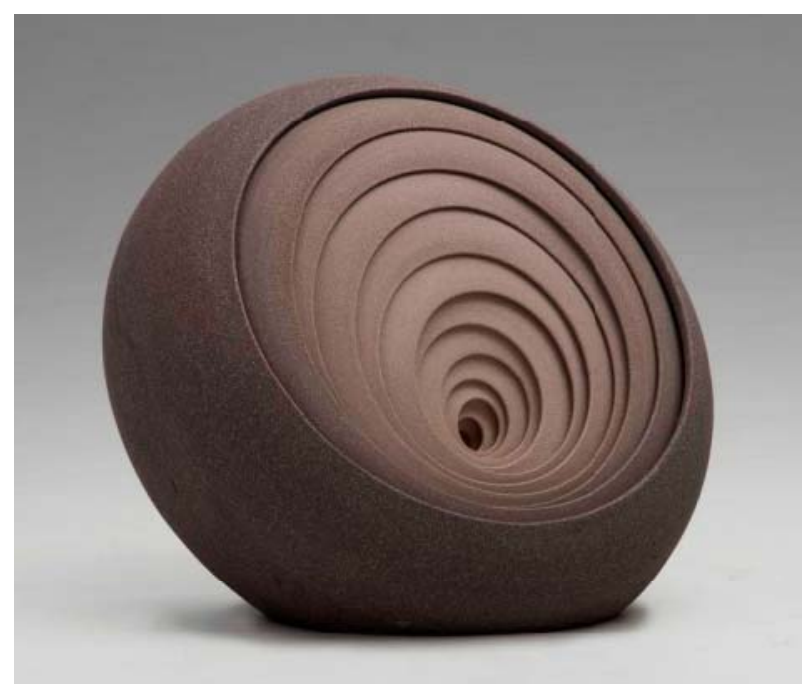

Figure 23. An example of Radial Hierarchy, "Increase II", Slant series, 2011 (URL21, 2016). 


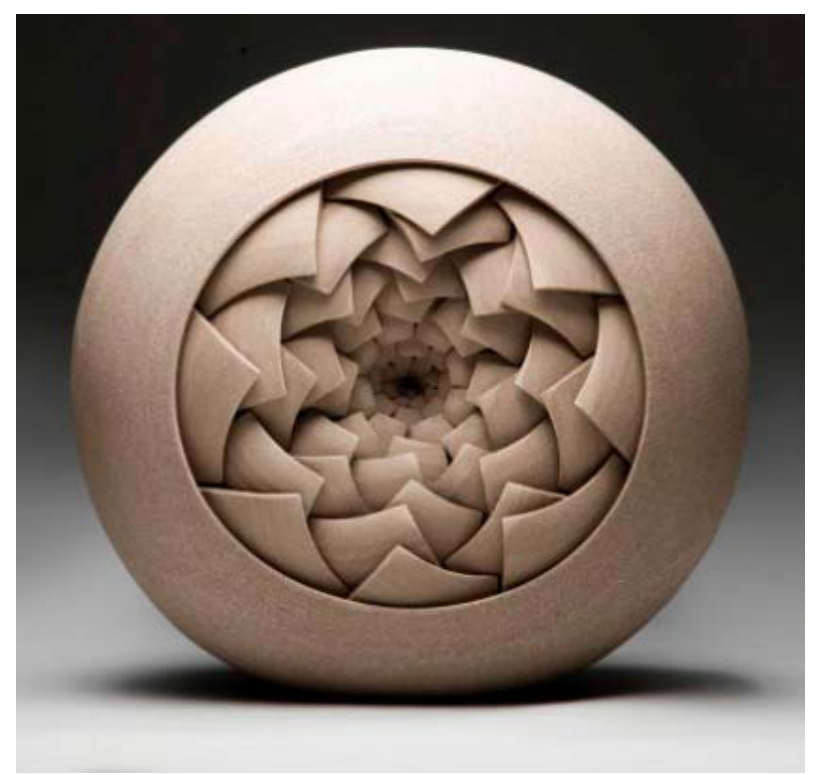

Figure 24. An example of Radial Hierarchy, “Bud III”, Fragmentation series, 2009 (URL22, 2016).

As it is seen above examples in which their central points are defined by forms, the repetitions of same units are expanding through the sides. These works of artist are artistic and they have no functions.

Matthew's works are mainly stem from the geometric and structural architecture current. Each part is continental forms which has the visual and tactual beauty and in which traditional processes are reflected through an abstract discovery. Apart from constructing a single form he constructed many layers through circular cross-sections. (URL23, 2016)

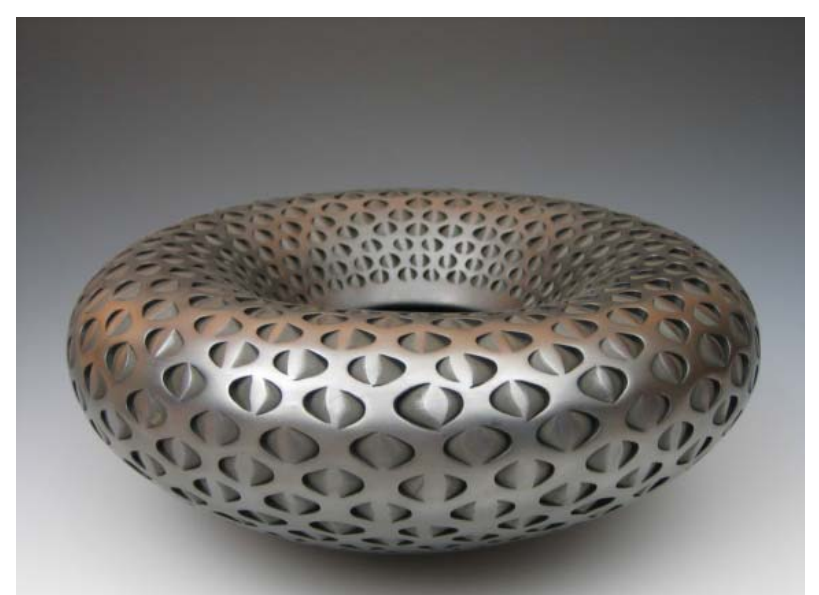

Figure 25. An example to Axial Hierarchy, "Metallicdonuteyeweave", Michael Wisner, $17.5 \times 22.5 \mathrm{~cm}, 2004$ (Wood, 2006, pp. 74-77). 


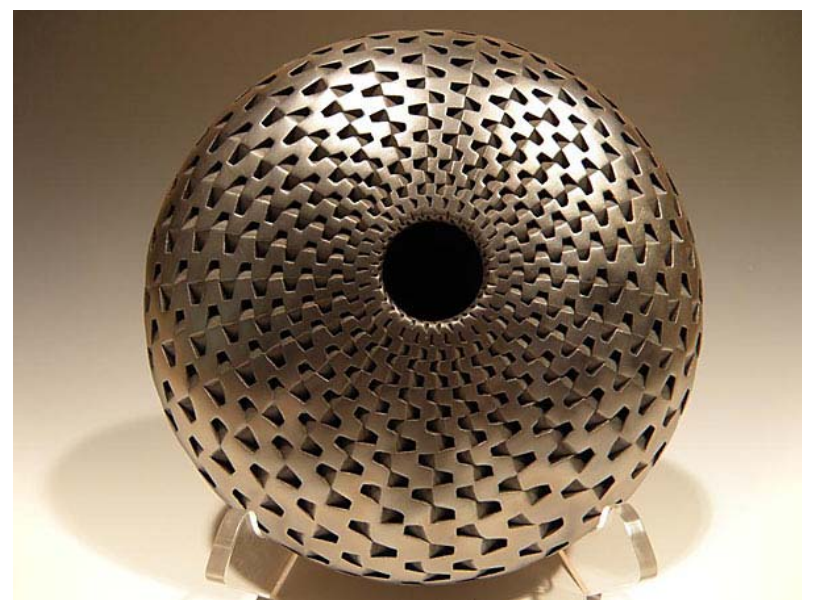

Figure 26. An example to Radial Hierarchy, "Blackspoke”, Michael Wisner, 2010 (URL24, 2016).

The compositions made up by reliefs which are sequenced through an axe on the surface from bigger to smaller or vice versa are the example of Axial Hierarchy and at the same time Radial Hierarchy (see Figures 23 and 24). Above, while each line of the reliefs creates Axial Hierarchy, when it is looked from the top it can be seen they are gathered around a centre. Therefore they are the example of Radial Hierarchy.

Michael inspired from antique Anasazi and Mimbres ceramics, has started to make southwest pots nearly 20 years ago. Also Woody Creek, took native clays near to his studio then filtered these clays and he formed each part with his hand. In the light of his traditions they made modern and continental works and the deep effect in their work has taken an incomparable position. The rhythmic textures and patterns they create on metal tools made each piece unique. (URL25, 2016)

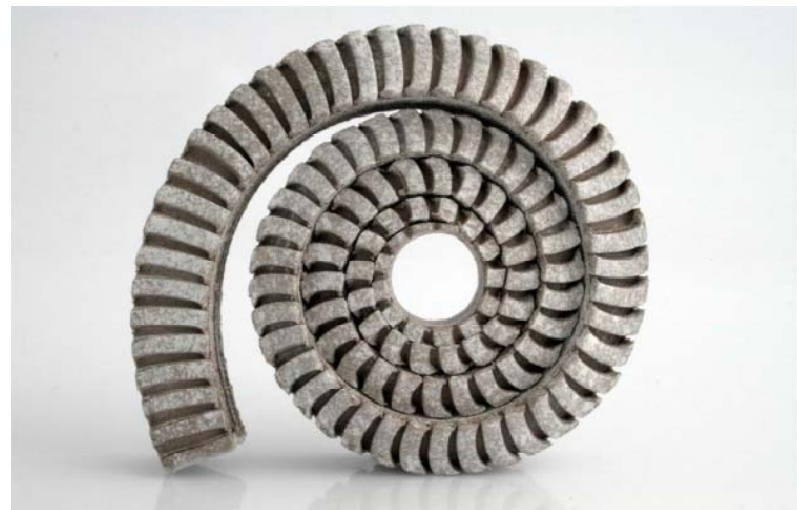

Figure 27. An example to Radial Hierarchy, “3D-Lines”, Petra Wolf, 2011 (URL26, 2016).

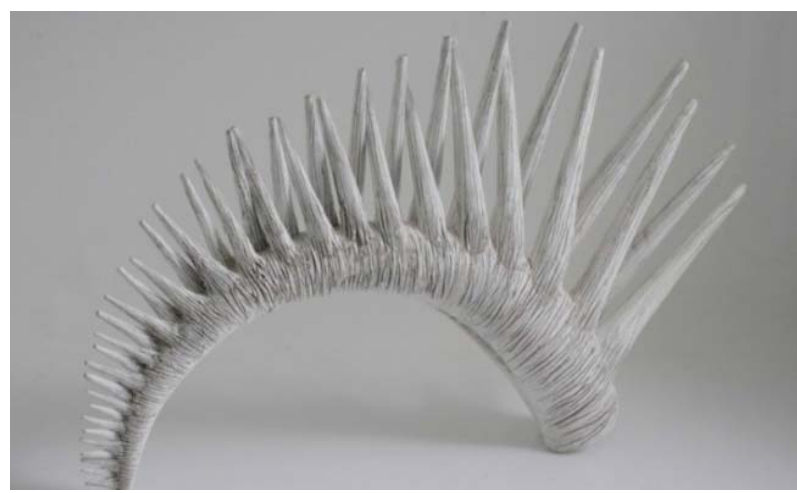

Figure 28. An example of Axial (linear) Hierarchy, Petra Wolf (URL27, 2016). 
Petra Wolf's work seen on the right above is an example of Radial Hierarchy. Although the arrangement turns as spiral it has a central point and there is a grading from bigger to smaller. It consists of ceramic bars which are graded on contiguous to form's surface. The work left above is the example of Pheripheral Hierarchy, at the same time it also creates Axial Hierarchy by its ceramic bars sequenced through an axe.

"Artist, was born in 1957. The artist who takes 12 awards till 1987, also has various works among public collections" (URL28, 2016).

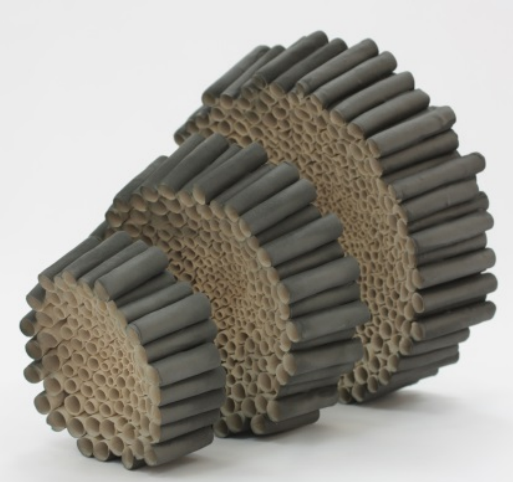

Figure 29. Example to Axial Hierarchy in Form, "Holes", $11.5140 \times 5 \mathrm{~cm}, 16 \times 18.5 \times 6.5 \mathrm{~cm}, 22 \times 25.5 \times 8 \mathrm{~cm}$, Casting technique, $1,200^{\circ} \mathrm{C}$, Kadir Ertürk, 2011.

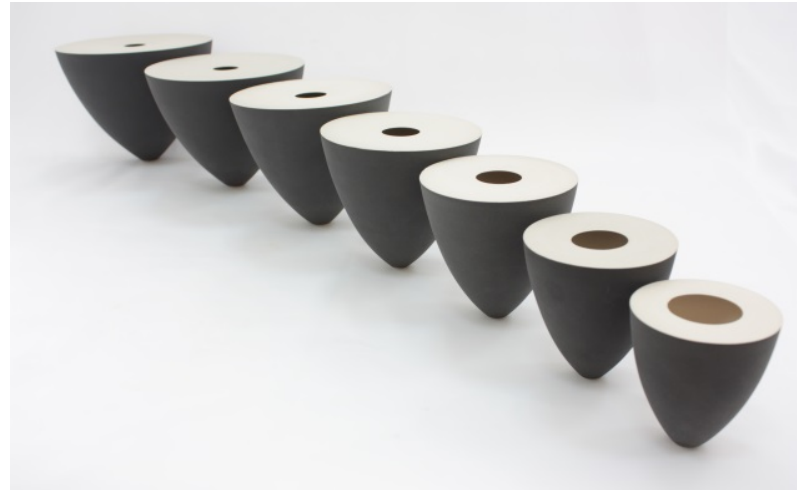

Figure 30. Example to Axial Hierarchy in Form, "Steps", $30 \times 120 \times 16 \mathrm{~cm}$, Casting technique, 1, 200 ${ }^{\circ} \mathrm{C}$, Kadir Ertürk, 2011 .

Above examples, taken from Kadir Ertürk's master thesis called "Research on Hierarchy which is a Concept Principle in Ceramics Art and Personal Interpretations", reflects Axial Hierarchy created by forms. The method at work is shaping with mould, and used bright and translucent liner on surface.

Plastic arts is a domain of art in which the number of the examples of koram is too much. In technical analysis there is a differentiation in meaning of form, length, colour, texture, surface and fiction. It is certain in these differentiations that there is an order although there are different forms of sequence.

\section{Conclusion}

Human kind along in the history has always been in search of a language in order to explain all kinds of emotional densities like herself, her environment, the social and cultural state which is located, her fears, her passions, her curiosity and beliefs. It chooses Plastic elements like painting, drawing, writing, and phonetic 
elements like songs, poems, rhymes and epos, performances like theaters, plays and rituals as its elements of language. While reflecting itself through its preferences, it also reflects a hierarchical system visually and spatially. This grading that we can say Hierarchy shortly, can be seen in every domain from management to architecture, nature, products. This system or figuration, many times addresses the visual aspect of its receptioners.

In the art of ceramic, Hierarchy has taken intensely on traditional and continental ceramic products and the Hierarchy and its types are examined (axial, radial and peripheral) according to the production methods of ceramic goods. Artistic ceramic and industrial ceramic are taken as the methods of production. Hierarchy is commonly seen in Industrial and artistic ceramic as axial, pheripheral and radialin forms or on surfaces and either in forms and on surfaces. It is seen that in industrial ceramic Hierarchy has only the functional properties. Traditional and continental artists who have different production styles and methods use different types of Hierarchy in their works. Hierarchy occurs in ceramic arts in a peculiar language. In art of ceramic Hierarchy is using in a wide area especially as textual, vitrified, functional or artistic and it is explored that it contributes an order, a visual aesthetic.

\section{References}

Alpaslan, S. A. (2003). Tasarım Mesleki Resim (Design Vocational Drawing), (1). İstanbul: Ya-Pa Yayınları. Deliduman, C. G., \& Orhon, B. İ. (2006). Temel sanat eğitimi. Istanbul: Gerhun Yayınları.

Güngör, İ. H. (1972). Temel tasarım (Basic Design), (Vol. 1). İstanbul.

Güngör, İ. H. (2005). Temel tasarım (Basic Design), (Vol. 3). Bilgisayar Destekli Bask1 ve Reklam Hizmetleri Sanayi ve Ticaret

Ltd. Şti., (Computer Aided Printing and Advertisement Services Industry and Trade Limited Company), Istanbul.

Hatch, M. (2010). Relative permanence. Ceramics Monthly, USA.

San, I. (2003). Sanat Eğitimi Kuramları (Arts Education Theories), (Vol. 2). Ankara: Utopya Yayınevi.

Wood, D. (2006). Evolving tradition, Ceramics Art and Perception, 63.

Yardımcı, İ. (1993). Anadolu'da Başlangıcından Günümüze Seramik-Metal Teknik ve Biçim Etkileşimleri, (YL), Eskişehir.

URL1 2016. http://www.vanseodesign.com/web-design/size-scale-proportion/

URL2 2016. http://listelio.com/bitkilerin-birbirinden-harika-ve-sasirtici-uyumlari/

URL3 2016. https://tr.pinterest.com/pin/184295809721341849/

URL4 2016. http://davidreport.com/200703/more-paper-art-from-jen-stark/

URL5 2016. http://altinorann.blogspot.com/2011/05/12-egrelti-otu.html

URL6 2016. http://homedesignminimalist.blogspot.com.tr/2011/05/waterside-canal-apartment-modern-split.html

URL7 2016. http://www.sifalibitkiler.us/archives/549

URL8 2016. https://www.littlebigshots.com.au/venue/sydney

URL9 2016. http://www.kemaluludag.com/kimliksorunu.asp

URL10 2016. http://www.karenswyler.com/

URL11 2016. http://ceramic-lab.com/post/85933058396/b22-design-ettore-sottsass-pair-of-yantra

URL12 2016. http://www.pietstockmans.com/home.php

URL13 2016. http://www.pietstockmans.com/home.php

URL14 2016. https://tr.pinterest.com/pin/138345019780569979/

URL15 2016. http://www.japantimes.co.jp/culture/2006/12/07/arts/new-forms-of-old-traditions-at-the-japan-society/\#.WE5li9Kcc

URL16 2016. http://www.mirviss.com/artists/yagi-akira

URL17 2016. http://www.annvanhoey-ceramics.be/work.html

URL18 2016. https://news.uwgb.edu/log-news/releases/09/03/gallery-faculty-lee-stehlik-10113/

URL19 2016. http://technotescollegeblog.blogspot.com.tr/2014/11/pamela-sunday-there-is-not-great-deal.html

URL20 2016http://hifructose.com/2014/02/26/harumi-nakashimas-biomorphic-ceramic-sculptures/

URL21 2016. http://matthewchambers.co.uk/\#/portfolio/4540696487

URL22 2016. http://matthewchambers.co.uk/\#/portfolio/4540696487 
URL23 2016. http://beveregallery.com/artists?artistID $=630$

URL24 2016. http://korologosgallery.com/a-true-roaring-fork-valley-piece-of-art/ URL25 2016. http://www.korologosgallery.com/artists/wisner/wisnerBio.html URL26 2011. http://www.neuewolfkeramik.de/index.php/Showroom.html URL27 2011. http://www.neuewolfkeramik.de/index.php/Showroom.html URL28 2011. http://www.neuewolfkeramik.de/index.php/biographie.html 